\title{
Association of vitamin D receptor ApaI gene polymorphism with osteoporosis susceptibility in postmenopausal Han Chinese women in Xinjiang
}

\author{
DEFENG MENG $^{1 *}$, XIAO DING $^{1 *}$, JIAOJIAO LAN $^{1}$, FANGLIANG PENG $^{1}$, WEIGUO ZHU $^{1}$, ZEYU CHENG $^{1}$, \\ HAORUO JIA ${ }^{1}$, HAO XU $^{1}$, CHENHUI SHI ${ }^{1}$, LIJUAN PANG ${ }^{2}$ and WEI SHAN WANG ${ }^{2}$ \\ Departments of ${ }^{1}$ Orthopedics and ${ }^{2}$ Pathology, The First Affiliated Hospital, \\ Shihezi University School of Medicine, Shihezi, Xinjiang 832000, P.R. China
}

Received December 5, 2017; Accepted September 20, 2018

DOI: $10.3892 /$ br.2018.1155

\begin{abstract}
Osteoporosis is a polygenic disorder and has been demonstrated to be associated with $\sim 30$ candidate genes, the majority of which have also been implicated in the regulation of bone mineral density (BMD). Vitamin D receptor (VDR) is the candidate gene that has been most extensively studied. Certain studies have reported that the VDR single nucleotide polymorphism ApaI is associated with the risk of osteoporosis in Caucasian and African women. However, this association has not yet been studied in postmenopausal Han Chinese women in the Xinjiang area. In the present study, ApaI polymorphisms of VDR were defined by polymerase chain reaction-restriction fragment length polymorphism, in order to analyze the distribution of ApaI polymorphisms in postmenopausal Han Chinese women from Xinjiang. BMD was measured by dual energy X-ray absorptiometry at the lumbar spine (L2-4), Ward's triangle, great trochanter and femoral shaft. A total of 336 women were included in this study. The genotype distribution of ApaI was consistent with the Hardy-Weinberg equilibrium (all $\mathrm{P}>0.05$ ). There were no significant differences in ApaI genotype frequencies between the 90 cases in the osteoporosis group and 246 cases in the non-osteoporosis group $(\mathrm{P}=0.946)$. Meanwhile, it was identified that BMD values of the tested locations were negatively correlated with age $(\mathrm{P}<0.05)$ and positively correlated with body mass index (BMI; $\mathrm{P}<0.05)$. On further attribution risk analysis, BMD was identified as a risk factor [odds ratio (OR): 0.464, 95\%
\end{abstract}

Correspondence to: Professor Wei Shan Wang or Professor Lijuan Pang, Department of Pathology, The First Affiliated Hospital, Shihezi University School of Medicine, 107 North Second Road, Shihezi, Xinjiang 832000, P.R. China

E-mail: 448342428@qq.com

E-mail: ocean123456@163.com

*Contributed equally

Key words: gene polymorphism, ApaI, osteoporosis, bone mineral density, body mass index confidence interval $(\mathrm{CI})$ : $0.372-0.580, \mathrm{P}=0.001]$ and $\mathrm{BMI}$ a protective factor (OR: $1.502,95 \% \mathrm{CI}$ : $1.008-2.240, \mathrm{P}=0.032$ ) in osteoporosis. When BMD was adjusted for confounding factors including age and BMI, it was observed that the ApaI polymorphism was not associated with BMD at the sites tested $(\mathrm{P}>0.05)$. In conclusion, the present study identified no significant association of the common VDR polymorphism ApaI with BMD at several skeletal sites in postmenopausal Han Chinese women in the Xinjiang area. Age was negatively correlated with BMD at different sites and identified as a risk factor; while BMI was positively correlated with BMD and identified as a protective factor.

\section{Introduction}

Osteoporosis is a metabolic bone disease that may be defined as a systemic skeletal destruction characterized by low bone mass, high bone friability and micro-architectural decline of bone tissue (1). Clinical manifestations are easy occurrence of bone fracture and relatively high rates of mortality and disability caused by hip, extremity and vertebral fractures. Osteoporosis has become a major public health issue and is a burden to patients, their families and society (2).

The pathophysiological mechanism of osteoporosis is complex (3). The reconstruction of bone tissue is a key process in maintaining the microstructure and morphology of bone (4,5). Imbalances in the bone tissue reconstruction process can manifest as upregulation in the process of bone resorption by osteoclasts, and reduced osteoblast formation of bone tissue (6). This results in systemic loss of bone mass, increased bone fragility, decreased bone mineral density (BMD), increased risk of bone destruction and osteoporosis (7).

In 2004, the World Health Organization recommended that the diagnosis of osteoporosis be performed based on values of BMD or bone mineral content (BMC) (8): Normal BMD or $\mathrm{BMC}$ is within one standard deviation (SD) of the average bone density in normal adults; BMD is usually expressed as a $\mathrm{T}$-value $(\mathrm{T}$-score $)$, where $\mathrm{T}$-value $=($ measured value - mean value in normal adults of the same gender)/SD of the mean BMD of normal adults of the same sex and gender. The World Health Organization sets the average body mass of adults 
with normal BMD as the standard, and defines osteoporosis when BMD is $\geq-2.5 \mathrm{SD}$ units in postmenopausal women or men $>50$ years (normal population: T-score $\leq-1 \mathrm{SD}$; bone mass loss population: $-1 \mathrm{SD}<\mathrm{T}$-Score $<-2.5 \mathrm{SD}$; osteoporosis population: T-Score $\geq-2.5 \mathrm{SD}$ ). Through the study of changes in BMD, numerous factors affecting the BMD value have been identified, including estrogen, osteoprotegerin, calcitonin, transforming growth factor, thyroid hormone and gene polymorphisms (9-11).

Previous studies have demonstrated that genetic factors may be associated with BMD and serve an important role in the pathogenesis of osteoporosis (12). Data originating from the study of twins has indicated genetic factors account for up to $85 \%$ of diversity in bone mass (8). Numerous research institutions have investigated potential associations between candidate gene polymorphisms and osteoporosis $(3,6,7)$. The vitamin D receptor (VDR) gene polymorphism is one of the most widely studied, and has been indicated to be involved in bone mineral homeostasis, bone remodeling and bone matrix composition (14). Population-based and case-control studies have similarly identified polymorphisms in several candidate genes associated with bone mass or osteoporotic fracture, including VDR $(6,13,15)$.

VDR is a nuclear transcription factor that mediates the action of 1,25-dihydroxyvitamin D3 and affects calcium absorption, bone remodeling and mineralization rate. It is located on the long arm of 12 chromosome (3q11) and consists of 11 exons, 2-9 of which are actively transcribed (16). Several sites have been associated with BMD in the VDR gene, including ApaI, BsmI, FokI and TaqI (17). The ApaI and BsmI sites are both in intron 8 of the VDR gene (18). A number of studies $(16,17,19)$ have been undertaken in this field [Morrison et al (19) was the first to document an association between the VDR genotype and bone mass], but the results have been controversial and no clear correlation between ApaI gene polymorphism and osteoporosis has been identified. Vladoiu et al (20) reported that ApaI polymorphisms in the VDR gene have different phenotypes, which were associated with significantly different BMD values, suggesting that it may be used as a genetic marker to predict the risk of osteoporosis. Mitra et al (21) identified an association between BsmI and ApaI polymorphisms and BMD in postmenopausal Indian women, further suggesting that genetic background serves a role. However, other reports have observed conflicting results. Castelán-Martínez et al (22) documented that there was no clear correlation between BMD and ApaI polymorphism in postmenopausal women in Mexico. Feskanich et al (23) identified that genetic polymorphisms of ApaI did not affect the risk of osteoporosis.

Another important factor affecting BMD is estrogen level. Estrogen uses different pathways to regulate biological activity through the transduction of specific target cell signals. Rooney and van der Meulen (24) identified that estrogen exerted its effects primarily through the use of non-canonical pathways, to thus induce anti-osteoclast death or inhibit osteoblast death. Therefore, to minimize the effect of estrogen on BMD changes, postmenopausal women were selected for the present study purposes.

To the best of our knowledge, there are no previous studies of gene polymorphisms in postmenopausal Han women in
Xinjiang. The purpose of the present study was to investigate the potential association between the commonly studied polymorphism in the VDR gene, ApaI, and osteoporosis in postmenopausal women of Han nationality in Xinjiang. In this study, the polymerase chain reaction (PCR)-restriction fragment length polymorphism (RFLP) technique was used to verify genotypes of the ApaI locus of the VDR gene. The different genotypes were compared and BMD values were used to determine the impact of ApaI gene polymorphisms on osteoporosis, as in previous study of the association between BMD and genotype (25). Based on this line of research, it is hoped that screening and diagnosis of high-risk populations with osteoporosis may support the prevention of osteoporosis at the molecular level.

\section{Materials and methods}

Study population. Participants included 336 unrelated postmenopausal women who were recruited voluntarily from January to June 2016. The group included 90 women $(67.2 \pm 8.6$ years old; T-score $\geq-2.5 \mathrm{SD})$ with osteoporosis and 246 healthy individuals $(65.5 \pm 7.6$ years old; T-score $<-2.5 \mathrm{SD})$. Participants were recruited from the First Affiliated Hospital of Shihezi University (Shihezi, China), the People's Hospital of Xinjiang Uygur Autonomous Region (Urumqi, China), the People's Liberation Army 474 Hospital and Xinjiang Production and Construction Corps Hospital (Urumqi, China). Patients with secondary osteoporosis diseases (diabetes, Cushing's syndrome, thyroid, nutrition deficiency, myeloproliferative diseases, bone tumors, connective tissue diseases and congenital diseases), hepatic renal dysfunction and incomplete clinical data were excluded.

The protocol of the present study was approved by the Institutional Medical Ethics Committee of Shihezi University, and all participants received and signed informed consent documents.

Laboratory analysis. Genotyping was performed by researchers who were blinded to the case/control status of the study subjects. Blood samples $(3 \mathrm{ml})$ were collected in EDTA tubes and frozen in liquidnitrogen for $2 \mathrm{~h}$ aftercollection.GenomicDNA was extracted from peripheral white blood cells using a TIANamp Blood DNA Maxi kit (Tiangen Biotech Co., Ltd., Beijing, China), according to the manufacturer's protocol. A 740-bp fragment containing the ApaI polymorphism was amplified by PCR using specific primers (forward, 5'-CAGAGCATGGACAGGGAGCAA-3' and reverse, 5'-TCATGGCTGAGGTCTCAAGGG-3') as described previously (13). The thermocycler conditions were $95^{\circ} \mathrm{C}$ for $3 \mathrm{~min}$, followed by 35 cycles of $94^{\circ} \mathrm{C}$ for $30 \mathrm{sec}, 65^{\circ} \mathrm{C}$ for $30 \mathrm{sec}$ and $72^{\circ} \mathrm{C}$ for $30 \mathrm{sec}$, and ending with $72^{\circ} \mathrm{C}$ for $10 \mathrm{~min}$ (Eppendorf Mastercycler Gradient; Eppendorf, Hamburg, Germany). The 740-bp product fragment containing the ApaI polymorphism was digested with ApaI endonuclease (Thermo Fisher Scientific, Inc.). The ApaI fragments of the VDR gene were separated by $1.5 \%$ agarose gel electrophoresis with ethidium bromide staining. The genotypes were represented as AA (740 bp), Aa (740, 520 and $220 \mathrm{bp}$ ) and aa (520 and $220 \mathrm{bp}$ ) (26).

Densitometry study. BMD at the lumbar spine (L1-L4), Ward's triangle, great trochanter and femoral shaft were measured 
Table I. Frequency distribution of ApaI genotypes and alleles.

Frequency of total, n (\%)

\begin{tabular}{|c|c|c|c|c|c|c|c|}
\hline \multirow[b]{2}{*}{ Gene } & \multicolumn{4}{|c|}{ Genotype } & \multicolumn{3}{|c|}{ Allele } \\
\hline & Total, n & AA & $\mathrm{Aa}$ & aa & Total, $\mathrm{n}$ & A & $\mathrm{a}$ \\
\hline ApaI & 336 & $21(6.3)$ & $94(28.0)$ & $221(65.8)$ & 672 & $136(20.2)$ & $536(79.8)$ \\
\hline
\end{tabular}

Table II. Frequency distribution of ApaI genotypes and alleles in the osteoporosis and control groups.

\begin{tabular}{|c|c|c|c|c|c|}
\hline & \multicolumn{2}{|c|}{ Control $(n=246)$} & \multicolumn{3}{|c|}{ Osteoporosis $(n=90)$} \\
\hline & $\mathrm{n}$ & Frequency, \% & $\mathrm{n}$ & Frequency, \% & P-value \\
\hline \multicolumn{6}{|c|}{ Genotype } \\
\hline AA & 16 & 6.5 & 5 & 5.6 & \\
\hline $\mathrm{Aa}$ & 69 & 28.0 & 25 & 27.8 & \\
\hline aa & 161 & 65.4 & 60 & 66.7 & 0.946 \\
\hline \multicolumn{6}{|c|}{ Allele } \\
\hline A & 101 & 20.5 & 35 & 19.4 & \\
\hline $\mathrm{a}$ & 391 & 79.5 & 145 & 80.6 & \\
\hline
\end{tabular}

using a dual-energy X-ray absorptiometry (DXA) scanner (GE Lunar DPX Prodigy; GE Healthcare, Chicago, IL, USA) (6). BMD was calculated by dividing BMC (g) by bone area $\left(\mathrm{cm}^{2}\right)$, and expressed as $\mathrm{g} / \mathrm{cm}^{2}(8)$. By comparing with the $\mathrm{SD}$ of BMD in the normal reference population, the T-score of BMD in participants was calculated to determine the diagnosis of osteoporosis (normal population: T-score $\leq-1 \mathrm{SD}$; bone mass loss population: $-1 \mathrm{SD}<\mathrm{T}$-Score <-2.5 SD; osteoporosis population: T-Score $\geq-2.5 \mathrm{SD})$. Grouping was based on measurement results. Additionally, body weight and height were measured to calculate body mass index (BMI).

Statistical analysis. Statistical analysis of the results was performed with SPSS 20.0 (IBM Corp., Armonk, NY, USA). For analysis of subject characteristics, quantitative data were presented as means \pm standard deviation. The Hardy-Weinberg equilibrium (HWE) distribution of the ApaI allelic and genotypic frequencies was assessed with the $\chi^{2}$ test. One-way analysis of variance was used to compare between different genotypes followed by the Bonferroni's post hoc test. Analysis of co-variance (ANCOVA) was used to compare the VDR genotypes adjusted for co-variants age and BMI. Genotypic frequencies were not normally distributed, and a bootstrap procedure was applied to the ANCOVA test. In this case, comparisons were performed with a non-parametric Kruskal Wallis test. Unconditional multivariable logistic regression models were used to measure the association of age and BMI with BMD. Age and BMI as risk factors for osteoporosis were assessed via odds ratios (ORs) and 95\% confidence intervals (CIs). In all analyses, significance was defined at $\mathrm{P}<0.05$.

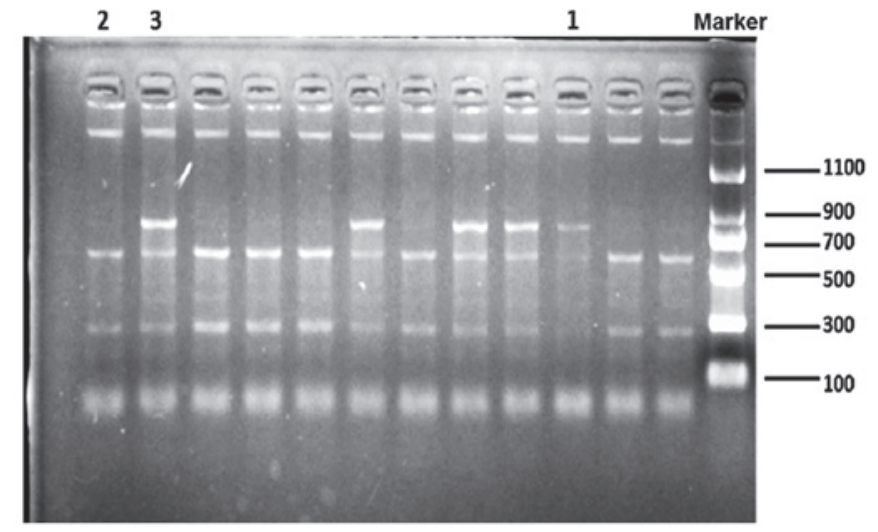

Figure 1. Enzyme digestion results of ApaI. Marker, DNA ladder (100-1,100 bp); lane 1, AA (740 bp); lane 2, aa (520 and 220 bp); lane 3, Aa (740, 520 and $220 \mathrm{bp})$.

\section{Results}

Genotypes and alleles. A total of 336 females were included in the study. The overall ApaI allelic and genotypic frequencies are listed in Table I. Frequencies of ApaI included in the analysis were consistent with the HWE $(\mathrm{P}>0.05)$. The enzyme digestion of ApaI was analyzed by agarose gel electrophoresis to examine band size consistency and confirm variants of the gene (Fig. 1).

Among the 90 patients with osteoporosis, the frequency distribution of ApaI genotypes was 5 (5.6\%) individuals with AA, 25 (27.8\%) with Aa and 60 (66.6\%) with aa. Among the 246 participants in the control group, the frequency distribution of ApaI genotypes was $16(6.5 \%)$ individuals with AA, $69(28.0 \%)$ with Aa and $161(65.4 \%)$ with aa (Table II). Data analysis indicated no significant association between ApaI genotype and osteoporosis $(\mathrm{P}=0.946)$.

$B M D$ and genotype. The results of the DXA scan were uniformly recorded in accordance with BMD and T-score standards (Fig. 2). The ApaI genotype of patients and controls was not associated with BMD at any bone site tested (Table III). On further BMD analysis, following adjustment for potential confounding factors, including age, no significant differences in BMI were observed between the genotypes (Table IV).

Age/BMI and BMD. Using ANCOVA to compare age/BMI with $\mathrm{BMD}$, it was determined that age was negatively associated with BMD, and BMI positively associated with BMD at all bone sites tested (Table V and Figs. 3 and 4). Analysis of risk 
Table III. Comparison of BMD value between different ApaI genotypes in the osteoporosis and control groups.

\begin{tabular}{|c|c|c|c|c|c|c|c|c|}
\hline \multirow[b]{3}{*}{ Genotype } & \multicolumn{8}{|c|}{$\mathrm{BMD}, \mathrm{g} / \mathrm{cm}^{3}$} \\
\hline & \multicolumn{4}{|c|}{ Osteoporosis } & \multicolumn{4}{|c|}{ Control } \\
\hline & AA & Aa & aa & P-value & AA & Aa & aa & P-value \\
\hline Lumbar L2-L4 & $0.830 \pm 0.237$ & $0.845 \pm 0.175$ & $0.907 \pm 0.164$ & 0.383 & $1.087 \pm 0.153$ & $1.114 \pm 0.161$ & $1.124 \pm 0.140$ & 0.334 \\
\hline Ward's triangle & $0.497 \pm 0.073$ & $0.514 \pm 0.130$ & $0.554 \pm 0.145$ & 0.291 & $0.813 \pm 0.190$ & $0.746 \pm 0.169$ & $0.771 \pm 0.178$ & 0.153 \\
\hline Great trochanter & $0.565 \pm 0.060$ & $0.607 \pm 0.099$ & $0.624 \pm 0.115$ & 0.311 & $0.817 \pm 0.155$ & $0.780 \pm 0.141$ & $0.784 \pm 0.131$ & 0.138 \\
\hline Femoral shaft & $0.857 \pm 0.094$ & $0.913 \pm 0.129$ & $0.977 \pm 0.151$ & 0.446 & $1.176 \pm 0.166$ & $1.125 \pm 0.169$ & $1.133 \pm 0.155$ & 0.561 \\
\hline
\end{tabular}

Data are presented as the mean \pm standard deviation.

A

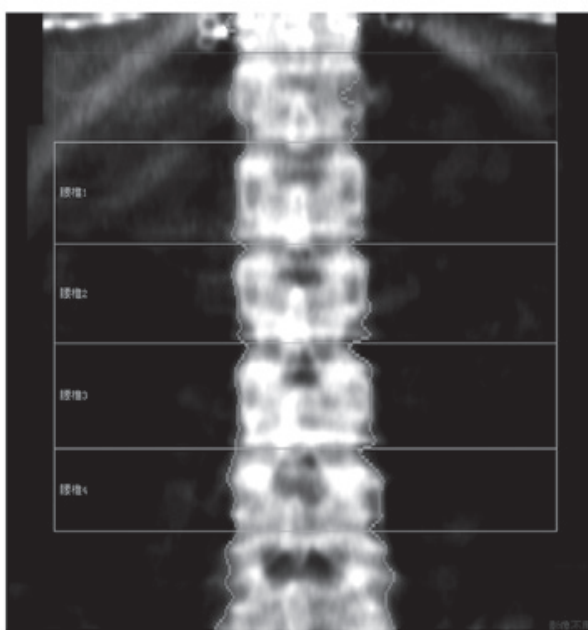

$\mathrm{C} \operatorname{BMD}\left(\mathrm{g} / \mathrm{cm}^{2}\right)$

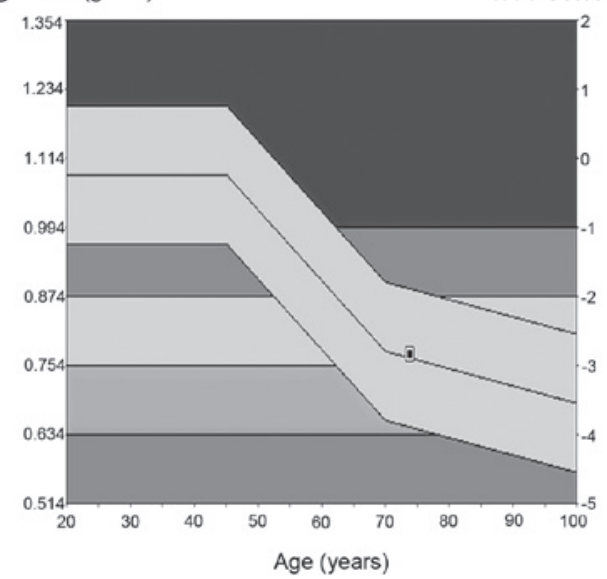

B

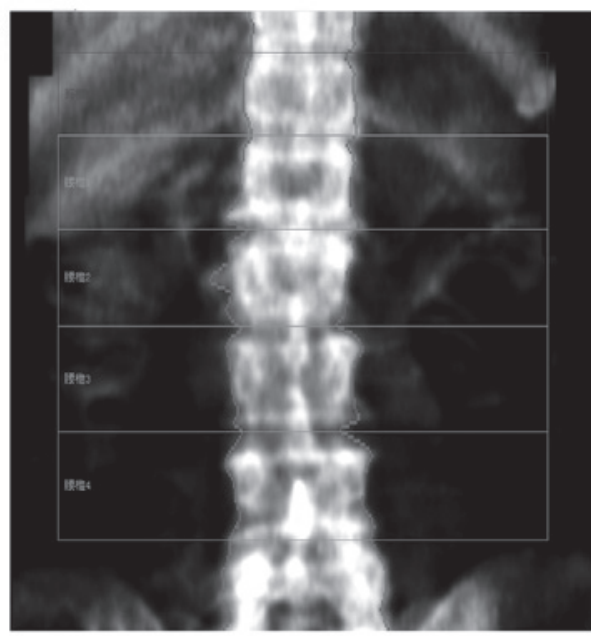

$\mathrm{D}_{\mathrm{BMD}\left(\mathrm{g} / \mathrm{cm}^{2}\right)}$

YA T-Score

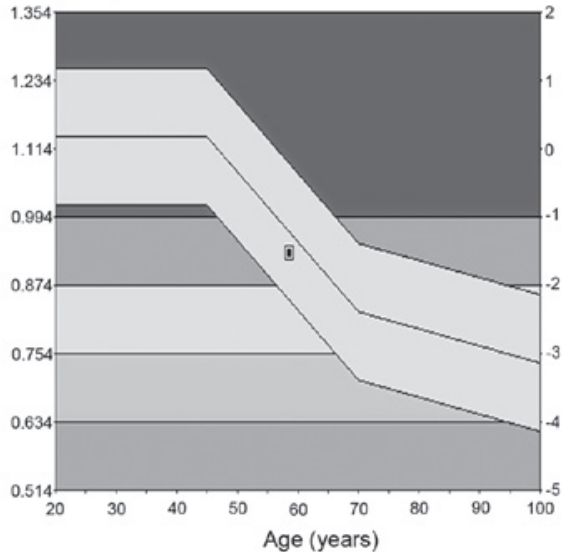

Figure 2. Spine forward bitmap of (A) normal bone density and (B) osteoporosis cases, and the corresponding data for bone mineral density in the (C) normal bone density and (D) osteoporosis cases.

factors indicated that age was a risk factor for osteoporosis (OR: $0.464,95 \% \mathrm{CI}: 0.372-0.580, \mathrm{P}=0.001)$, and BMI a protective factor in osteoporosis (OR: $1.502,95 \% \mathrm{CI}$ : $1.008-$ 2.240, $\mathrm{P}=0.032$; Table VI).

\section{Discussion}

Primary osteoporosis is the subject of ongoing research. At present it is established as a systemic metabolic disease affected by numerous factors (27). In general, osteoporosis occurs due to alterations in the number and activity of cells involved in bone metabolism, which itself is a process consisting of a balance between bone formation and bone destruction (28). Changes in bone tissue absorption and production, resulting in changes in BMD, cause a reduction in bone strength, fractures and osteoporosis (29). Previous study of osteoporosis has revealed that it is influenced by genetic factors (30). To the best of our knowledge, this is the first study to investigate 
Table IV. BMD at the lumbar spine L1-L4, Ward's triangle, great trochanter and femoral shaft according to VDR ApaI genotype.

\begin{tabular}{|c|c|c|c|c|c|c|c|c|}
\hline \multirow[b]{2}{*}{ Site } & \multicolumn{4}{|c|}{$\mathrm{BMD} 1, \mathrm{~g} / \mathrm{cm}^{2}$} & \multicolumn{4}{|c|}{$\mathrm{BMD} 2, \mathrm{~g} / \mathrm{cm}^{2}$} \\
\hline & $\mathrm{AA}(\mathrm{n}=21)$ & $\mathrm{Aa}(\mathrm{n}=94)$ & aa $(n=221)$ & P-value & $\mathrm{AA}(\mathrm{n}=21)$ & $\mathrm{Aa}(\mathrm{n}=94)$ & aa $(n=221)$ & P-value \\
\hline L1-L4 & $1.026 \pm 0.203$ & $1.043 \pm 0.203$ & $1.065 \pm 0.175$ & 0.454 & $1.011 \pm 0.084$ & $1.021 \pm 0.193$ & $1.014 \pm 0.139$ & 0.422 \\
\hline Ward's triangle & $0.738 \pm 0.217$ & $0.685 \pm 0.190$ & $0.712 \pm 0.195$ & 0.387 & $0.702 \pm 0.097$ & $0.602 \pm 0.132$ & $0.694 \pm 0.204$ & 0.331 \\
\hline Great trochanter & $0.758 \pm 0.176$ & $0.734 \pm 0.151$ & $0.741 \pm 0.145$ & 0.778 & $0.726 \pm 0.222$ & $0.669 \pm 0.142$ & $0.712 \pm 0.115$ & 0.717 \\
\hline Femoral shaft & $1.10 \pm 0.204$ & $1.068 \pm 0.184$ & $1.091 \pm 0.168$ & 0.537 & $0.991 \pm 0.102$ & $1.011 \pm 0.126$ & $1.112 \pm 0.122$ & 0.495 \\
\hline
\end{tabular}

Data are presented as the mean \pm standard deviation of the total cohort $(n=336)$. P-values were obtained by analysis of variance and analysis of covariance. BMD values are presented as BMD1 and BMD2, which denotes the raw BMD1 and BMD2 adjusted for body mass index and age, respectively. BMD, bone mass density.
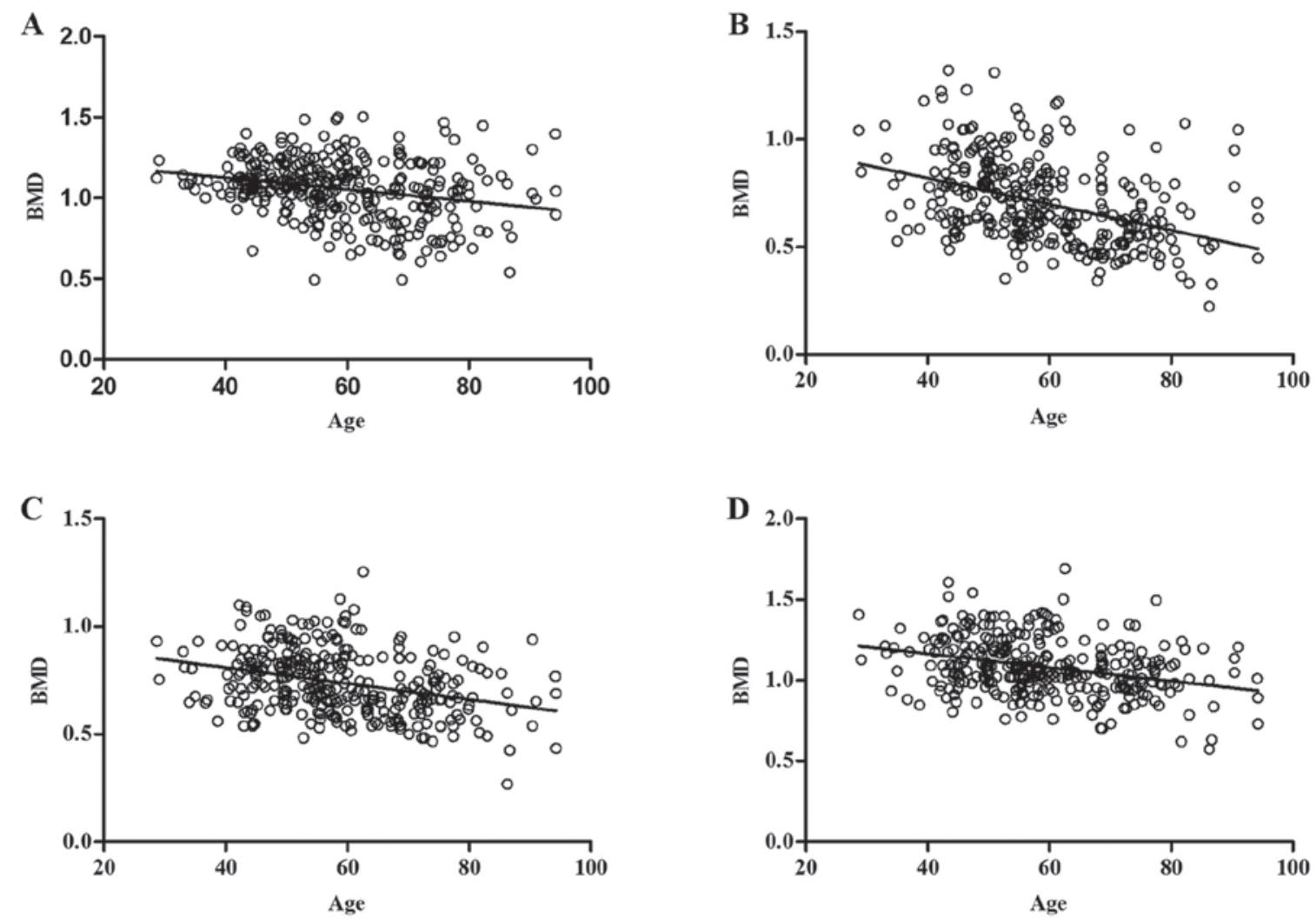

Figure 3. Curve estimation of age correlation with BMD at the (A) lumbar spine, (B) Ward's triangle, (C) great trochanter and (D) femoral shaft. BMD, bone mineral density.

the association between the ApaI polymorphism of the VDR gene and osteoporosis in postmenopausal Han females in the Xinjiang region. Through previous research, our group identified that osteoporosis is a multifactorial disease with a strong genetic component, and the results of this study are consistent with those of Zeljic et al (31), but genetic association studies in osteoporosis have reported conflicting results.

The present study identified that the distribution of ApaI genotypes and alleles in a population of Han Chinese postmenopausal women was consistent with HWE. The ApaI aa genotype was the most abundant, accounting for $65.8 \%$ of the total. Kang et al (32) reported that the ApaI genotype distributions in a South Korean population were $69.3 \%$ for aa, 25.4\% for Aa and 5.3\% for AA, which were similar to those of Han females in the present study. Sassi et al (33) reported that the frequencies of ApaI genotype distribution in a postmenopausal female Tunisian population were $15.5 \%$ for aa, $45.6 \%$ for Aa and $38.9 \%$ for AA, which differs markedly from the present study. The frequency distribution of the ApaI genotype in the present study was similar to that of Han women in urban areas including Guangzhou, Beijing and Harbin $(34,35)$. It is also consistent with the distribution of genotypes in countries including South Korea and Japan $(20,36)$. However, the distribution of gene frequency in populations from the USA and Europe, including Spain and Portugal $(37,38)$, exhibit significant differences, and marked difference has been identified in the frequencies of comparative genes between Uygur and Kazakh populations (39). Therefore, 

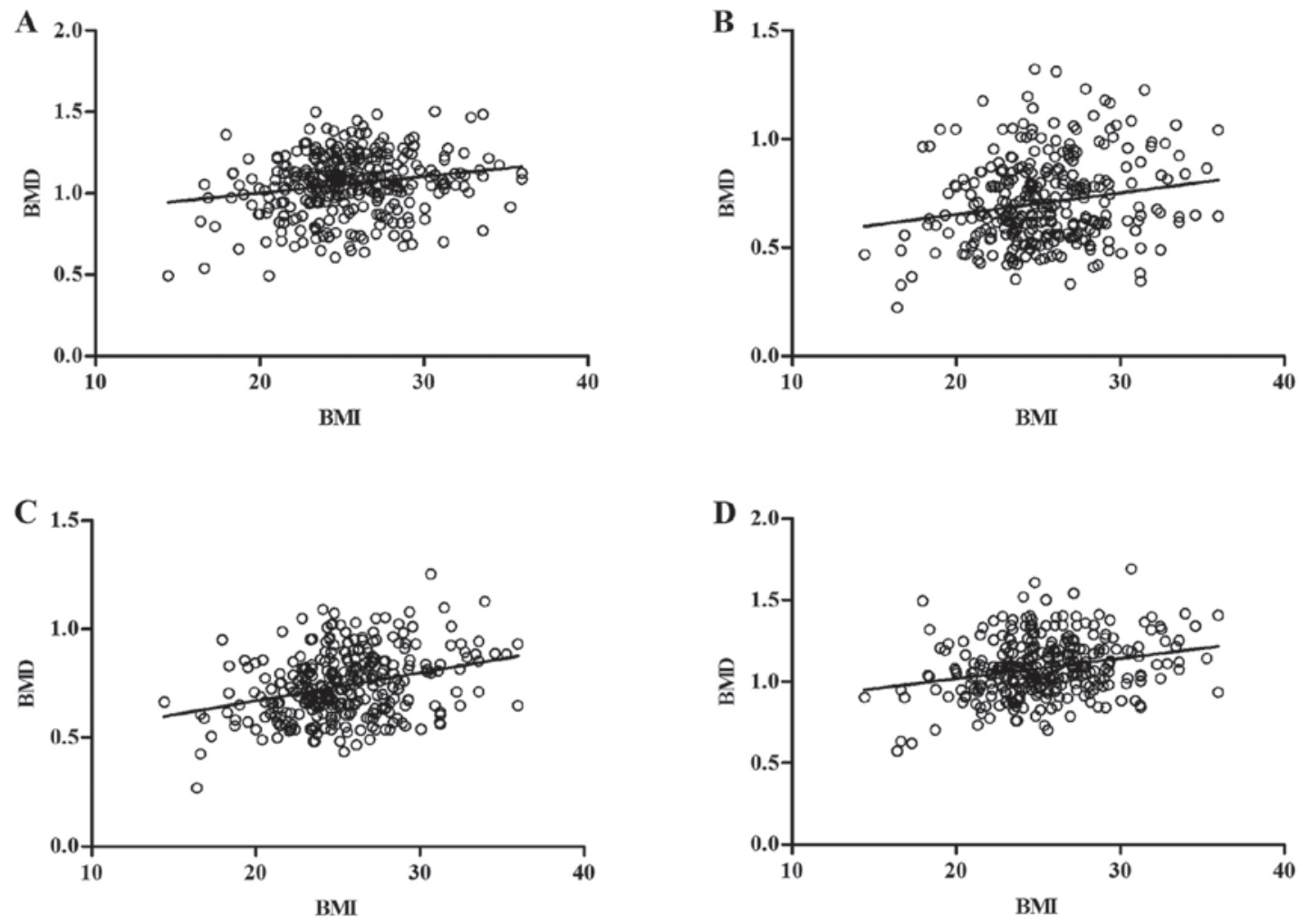

Figure 4. Curve estimation of BMI correlation with BMD at the (A) lumbar spine, (B) Ward's triangle, (C) great trochanter and (D) femoral shaft. BMD, bone mineral density; BMI, body mass index.

Table V. Correlation analysis of bone mineral density at different sites with age and BMI.

\begin{tabular}{lccccc}
\hline & \multicolumn{2}{c}{ Age } & & \multicolumn{2}{c}{ BMI } \\
\cline { 2 - 3 } \cline { 6 - 7 } Site & r & P-value & & r & P-value \\
\hline Lumbar spine & -0.316 & 0.00018 & & 0.195 & 0.00034 \\
Ward's triangle & -0.451 & 0.00022 & & 0.181 & 0.001 \\
Great trochanter & -0.373 & 0.00056 & & 0.309 & 0.00057 \\
Femoral shaft & -0.356 & 0.00017 & & 0.253 & 0.004 \\
\hline
\end{tabular}

BMI, body mass index.

the comparative analyses of gene frequency distributions in Mongolians and Caucasians have revealed that ApaI genotype may exhibit racial differences.

In the present study, there was a negative correlation between age and BMD at different sites. During aging, the body undergoes senescence. Bone tissue is among of the most affected parts of the body during the aging process (40). Therefore, the risk of senile osteoporosis increases with age (41). Additionally, a positive correlation was identified between BMI and BMD. The effect of BMI on bone tissue has been associated with the extent of weight-bearing pressure (37). The increase of pressure in individuals with high BMI can directly stimulate baroreceptors in the bone tissue (42). As a result, osteogenic differentiation may increase, the rate of bone resorption may decrease, ultimately accelerating bone formation and thereby increasing BMD and decreasing the risk of developing osteoporosis (43).

The present study identified no direct association between BMD and specific genotypes of the ApaI polymorphism. This is consistent with previous studies in different populations $(37,38,44)$. A lack of association has also been described by Moran et al (37) and Yu et al (44). However, there are previous studies associating the ApaI variant with increased risk of osteoporosis, including those by CastelánMartínez et al (22) and Pedrera-Canal et al (45). Therefore to date, studies have reported controversial results, and the effect of common ApaI polymorphisms on BMD is yet to be concluded.

It is likely that VDR gene expression is affected by environmental factors. Stathopoulou et al (16) suggested that calcium homeostasis may serve a role in this process. However, it should be noted that ApaI polymorphisms reportedly have no effect on protein expression, since they are located in the non-coding region of the VDR gene (45). The current results on ApaI polymorphisms support the proposal that population variants of a given genotype may be diverse and multifactorial (46). However, it was also demonstrated that there was no significant association between VDR ApaI polymorphisms and BMD in the studied population. Thus, further studies that investigate gene polymorphism and osteoporosis relevance would be beneficial to clinicians in diagnosing and preventing osteoporosis.

There were certain limitations in the present study. Firstly, patient sample size was relatively small compared with the total population in Xinjiang, and thus whether and how ApaI genotype influences bone microarchitecture requires 
Table VI. Analysis of age and BMI as osteoporosis risk factors.

\begin{tabular}{lcccrrr}
\hline Variable & $\beta$ & Standard error & Odds ratio & 95\% Confidence interval & Wald $\chi^{2}$ & P-value \\
\hline Age & -0.767 & 0.113 & 0.464 & $0.372-0.580$ & 0.001 \\
BMI & 0.407 & 0.204 & 1.502 & $1.008-2.240$ & 45.967 \\
\hline
\end{tabular}

BMI, body mass index.

further investigation in larger cohorts. Secondly, selection of samples was only conducted in Xinjiang, and therefore ApaI genetic polymorphism studies should be expanded to multiple regions and races to further investigate the associations with osteoporosis among different ethnicities. Thirdly, future studies in larger samples of post-menopausal women in Xinjiang should focus on multiple haplotypes, rather than single polymorphisms, to aid clarify the potential overall effects of common VDR polymorphisms.

In conclusion, no significant association between the common VDR polymorphism ApaI and BMD was observed at target skeletal sites in postmenopausal Han Chinese women in the Xinjiang area. Age was negatively associated with BMD at different sites and identified as a risk factor; while BMI was positively associated with BMD and identified as a protective factor.

\section{Acknowledgements}

The authors would like to thank Professor Xiaobin Cui at the Shihezi University School of Medicine (Shehezi, China) for his suggestions and assistance.

\section{Funding}

The present study was supported by the National Science Foundation of China (grant nos. 81760404, 81772407 and 81660374) and the Xinjiang Bingtuan Special Program (grant nos. 2014CC002 and 2016BC001).

\section{Availability of data and materials}

All data generated or analysed during this study are included in this published article.

\section{Authors' contributions}

$\mathrm{DM}$ and $\mathrm{XD}$ were responsible for conception and design of the study. HJ, JL, FP, HX and WZ were responsible for the acquisition of data and analysis and interpretation of the data. $\mathrm{ZC}, \mathrm{CS}, \mathrm{LP}$ and WW were involved in drafting the manuscript or revising it critically for important intellectual content. All authors read and approved the final version of the manuscript.

\section{Ethics approval and consent to participate}

The present study protocol was approved by the Institutional Medical Ethics Committee of Shihezi University (Shehezi, China), and all participants signed informed consent documents agreeing to their participation.

\section{Consent for publication}

All participants agreed in writing to the publication of associated data following anonymization.

\section{Competing interests}

The authors declare no competing interests.

\section{References}

1. Sabet FA, Raeisi Najafi A, Hamed E and Jasiuk I: Modelling of bone fracture and strength at different length scales: A review. Interface Focus 6: 20150055, 2016

2. Melton LJ III: Who has osteoporosis? A conflict between clinical and public health perspectives. J Bone Miner Res 15: 2309-2314, 2000.

3. Seremak-Mrozikiewicz A, Barlik M, Drews K, Bogacz A, Tatuśko J, Piotrowska A, Spaczyński M, Grześkowiak E and Mrozikiewicz PM: The genetic variants of RANKL/RANK/ OPG signal trial in postmenopausal women with osteopenia and osteoporosis. Arch Perinat Med 17: 72-80, 2011.

4. Barrett-Connor E, Siris ES, Wehren LE, Miller PD, Abbott TA Berger ML, Santora AC and Sherwood LM: Osteoporosis and fracture risk in women of different ethnic groups. J Bone Miner Res 20: 185-194, 2005.

5. Kim YD, Yim DH, Eom SY, Moon SI, Park CH, Kim GB, Yu SD, Choi BS, Park JD and Kim H: Differences in the susceptibility to cadmium-induced renal tubular damage and osteoporosis according to sex. Environ Toxicol Pharmacol 38: 272-278, 2014

6. Wang G, Yang J, Zheng X, Zhu J, Shi W, Chen A, Chen G and Zhou F: Association of genetic polymorphisms of GALNT3 and VDR with osteoporosis in postmenopausal women. Exp Ther Med 12: 2629-2633, 2016.

7. Wu J, Shang DP, Yang S, Fu DP, Ling HY, Hou SS and Lu JM: Association between the vitamin D receptor gene polymorphism and osteoporosis. Biomed Rep 5: 233-236, 2016.

8. Nakamura T: WHO diagnostic criteria for osteoporosis and trends in Europe and USA. Nihon Rinsho 62 (Suppl 2): 235-239, 2004 (In Japanese).

9. Pocock NA, Eisman JA, Hopper JL, Yeates MG, Sambrook PN and Eberl S: Genetic determinants of bone mass in adults. A twin study. J Clin Invest 80: 706-710, 1987.

10. Guéguen R, Jouanny P, Guillemin F, Kuntz C, Pourel J and Siest G: Segregation analysis and variance components analysis of bone mineral density in healthy families. J Bone Miner Res 10: 2017-2022, 1995

11. Krall EA and Dawson-Hughes B: Heritable and life-style determinants of bone mineral density. J Bone Miner Res 8: 1-9, 1993.

12. Zhao L, Liu WL, Liu Y and Zhao YX: Vascular endothelial dysfunction may be a common initial factor of development of vascular calcification and osteoporosis. Negative, 2017. http:// en.cnki.com.cn/Article_en/CJFDTotal-DSJY201701007.htm.

13. Liu L, Zhu Q, Wang J, Xi Q, Zhu H and Gu M: Gene expression changes in human mesenchymal stem cells from patients with osteoporosis. Mol Med Rep 12: 981-987, 2015.

14. Chen XE, Chen P, Chen SS, Lu J, Ma T, Shi G, Zhou Y, Li J and Sheng L: A population association study of vitamin D receptor gene polymorphisms and haplotypes with the risk of systemic lupus erythematosus in a Chinese population. Immunol Res 65: 750-756, 2017. 
15. Lee DO, Kim JH, Yoo BC and Yoo JH: Is osteoporosis a risk factor for ankle fracture? Comparison of bone mineral density between ankle fracture and control groups. Osteoporos Sarcopenia 3: 192-194, 2017.

16. Stathopoulou MG, Dedoussis GV, Trovas G, Theodoraki EV, Katsalira A, Dontas IA, Hammond N, Deloukas P and Lyritis GP The role of vitamin $\mathrm{D}$ receptor gene polymorphisms in the bone mineral density of Greek postmenopausal women with low calcium intake. J Nutr Biochem 22: 752-757, 2011.

17. Massidda M, Corrias L, Bachis V, Cugia P, Piras F, Scorcu M and Calò CM: Vitamin $\mathrm{D}$ receptor gene polymorphisms and musculoskeletal injuries in professional football players. Exp Ther Med 9: 1974-1978, 2015.

18. Colombini A, Brayda-Bruno M, Lombardi G, Croiset SJ, Ceriani C, Buligan C, Barbina M, Banfi G and Cauci S: BsmI, ApaI and TaqI polymorphisms in the vitamin D receptor gene (VDR) and association with lumbar spine pathologies: An Italian Case-Control Study. PLoS One 11: e0155004, 2016.

19. Morrison NA, Qi JC, Tokita A, Kelly PJ, Crofts L, Nguyen TV, Sambrook PN and Eisman JA: Prediction of bone density from vitamin D receptor alleles. Nature 367: 284-287, 1994

20. Vladoiu S, Oros S, Manda D, Rosca R and Ianas O: Vitamin D receptor, BsmI, FokI, ApaI, TaqI and estrogen receptor alpha, PvuII and XbaI, gene polymorphisms in women with osteoporosis. Endocrine Abstracts 32: P104, 2013.

21. Mitra S, Desai M and Ikram Khatkhatay M: Vitamin D receptor gene polymorphisms and bone mineral density in postmenopausal Indian women. Maturitas 55: 27-35, 2006.

22. Castelán-Martínez OD, Vivanco-Muñoz N, Falcón-Ramírez E Valdés-Flores M and Clark P: Apa1 VDR polymorphism and osteoporosis risk in postmenopausal Mexican women. Gac Med Mex 151: 472-476, 2015 (In Spanish).

23. Feskanich D, Hunter DJ, Willett WC, Hankinson SE, Hollis BW, Hough HL, Kelsey KT and Colditz GA: Vitamin D receptor genotype and the risk of bone fractures in women. Epidemiology 9: 535-539, 1998.

24. Rooney AM and van der Meulen MCH: Mouse models to evaluate the role of estrogen receptor $\alpha$ in skeletal maintenance and adaptation. Ann NY Acad Sci 1410: 85-92, 2017.

25. Horst-Sikorska W, Dytfeld J, Wawrzyniak A, Marcinkowska M, Michalak M, Franek E, Napiórkowska L, Drweska N and Słomski R: Vitamin D receptor gene polymorphisms, bone mineral density and fractures in postmenopausal women with osteoporosis. Mol Biol Rep 40: 383-390, 2013.

26. Dilmec F, Uzer E, Akkafa F, Kose E and van Kuilenburg AB: Detection of VDR gene ApaI and TaqI polymorphisms in patients with type 2 diabetes mellitus using PCR-RFLP method in a Turkish population. J Diabetes Complications 24: 186-191, 2010.

27. Becker W, Hujoel PP, Becker BE and Willingham H: Osteoporosis and implant failure: An exploratory case-control study J Periodontol 71: 625-631, 2000.

28. Noronha-Matos JB and Correia-de-Sá P: Mesenchymal stem cells ageing: Targeting the 'purinome' to promote osteogenic differentiation and bone repair. J Cell Physiol 231: 1852-1861, 2016.

29. Khaled EG, Saleh M, Hindocha S, Griffin M and Khan WS: Tissue engineering for bone production- stem cells, gene therapy and scaffolds. Open Orthop J 5 (Suppl 2): 289-295, 2011.

30. Özbaş H, Tutgun Onrat S and Ozdamar K: Genetic and environmental factors in human osteoporosis. Mol Biol Rep 39: 11289-11296, 2012.

31. Zeljic K, Elkilany A, Supic G, Surbatovic M,Djordjevic D, Magic Z and Bozic B: Vitamin D receptor gene polymorphisms association with the risk of sepsis and mortality. Int J Immunogenet 44: 129-134, 2017.
32. Kang TJ, Jin SH, Yeum CE, Lee SB, Kim CH, Lee SH, Kim KH, Shin ES and Chae GT: Vitamin D receptor gene TaqI, BsmI and FokI polymorphisms in Korean patients with tuberculosis. Immune Netw 11: 253-257, 2011.

33. Sassi R, Sahli H, Souissi C, El Mahmoudi H, Zouari B, Ben Ammar ElGaaied A, Sellami S and Ferrari SL: Association of LRP5 genotypes with osteoporosis in Tunisian post-menopausal women. BMC Musculoskelet Disord 15: 144, 2014.

34. Wang P, Ma LH, Wang HY, Zhang W, Tian Q, Cao DN, Zheng GX and Sun YL: Association between polymorphisms of vitamin D receptor gene ApaI, BsmI and TaqI and muscular strength in young Chinese women. Int J Sports Med 27: 182-186, 2006.

35. Zintzaras E, Rodopoulou P and Koukoulis GN: BsmI, TaqI, ApaI and FokI polymorphisms in the vitamin D receptor (VDR) gene and the risk of osteoporosis: a meta-analysis. Dis Markers 22 317-326, 2006.

36. Saito M, Eiraku N, Usuku K, Nobuhara Y, Matsumoto W, Kodama D, Sabouri AH, Izumo S, Arimura K and Osame M: ApaI polymorphism of vitamin $\mathrm{D}$ receptor gene is associated with susceptibility to HTLV-1-associated myelopathy/tropical spastic paraparesis in HTLV-1 infected individuals. J Neurol Sci 232: 29-35, 2005

37. Moran JM, Pedrera-Canal M, Rodriguez-Velasco FJ, Vera V, Lavado-Garcia JM, Fernandez P and Pedrera-Zamorano JD: Lack of association of vitamin D receptor BsmI gene polymorphism with bone mineral density in Spanish postmenopausal women. PeerJ 3 (Suppl 3): e953, 2015.

38. Rocha O, Lunet N, Costa L and Barros H: Osteoporosis treatment in Portugal: Trends and geographical variation. Acta Med Port 19: 373-380, 2006 (In Portuguese)

39. Pei FH, Wang YJ, Gao SL, Liu BR, Du YJ, Liu W, Yu HY, Zhao LX and Chi BR: Vitamin D receptor gene polymorphism and ulcerative colitis susceptibility in Han Chinese. J Dig Dis 12: 90-98, 2011.

40. Alonso N and Ralston SH: Unveiling the mysteries of the genetics of osteoporosis. J Endocrinol Invest 37: 925-934, 2014.

41. Marshall LM, Lang TF, Lambert LC, Zmuda JM, Ensrud KE and Orwoll ES; Osteoporotic Fractures in Men (MrOS) Research Group: Dimensions and volumetric BMD of the proximal femur and their relation to age among older U.S. men. J Bone Miner Res 21: 1197-1206, 2006

42. Palermo A, Tuccinardi D, Defeudis G, Watanabe M, D'Onofrio L, Lauria Pantano A, Napoli N, Pozzilli P and Manfrini S: BMI and BMD: The potential interplay between obesity and bone fragility. Int J Environ Res Public Health 13: E544, 2016.

43. Bijelic R, Balaban J and Milicevic S: Correlation of the lipid profile, BMI and bone mineral density in postmenopausal women. Mater Sociomed 28: 412-415, 2016.

44. Yu M, Chen GQ and Yu F: Lack of association between vitamin D receptor polymorphisms ApaI (rs7975232) and BsmI (rs1544410) and osteoporosis among the Han Chinese population: A meta-analysis. Kaohsiung J Med Sci 32: 599-606, 2016.

45. Pedrera-Canal M, Moran JM, Vera V, Roncero-Martin R, Lavado-Garcia JM, Aliaga I and Pedrera-Zamorano JD: Common allelic variants of the vitamin receptor D gene rs7975232 (ApaI) do not influence bone mineral density figures in postmenopausal osteoporotic women. Int J Clin Exp Med 8: 8173-8177, 2015.

46. Arji N, Busson M, Iraqi G, Bourkadi JE, Benjouad A, Bouayad A, Mariaselvam C, Salah S, Fortier C, Amokrane K, et al: Genetic diversity of TLR2, TLR4, and VDR loci and pulmonary tuberculosis in Moroccan patients. J Infect Dev Ctries 8: 430-440, 2014.

This work is licensed under a Creative Common Attribution-NonCommercial-NoDerivatives 4.0 International (CC BY-NC-ND 4.0) License. 